\title{
Elder abuse: Screening in Iranian families
}

\author{
Zahra Hosseinkhani ${ }^{1,4}$, Zhila Moradi², Farzad Khodamoradi*3,4 \\ Received: 24 Jan 2017 \\ Published: 25 Dec 2017
}

\begin{abstract}
Background: The rate of elder abuse has been increasing worldwide. This study aimed at identifying the group of elders susceptible to abuse and determining the influential factors of elder abuse.

Methods: A total of 683 elders, living in rural and urban areas of Qazvin (Iran), participated in this cross- sectional study that was conducted during September to December 2015. They were selected by stratified multistage random sampling method and filled in a standard questionnaire (H-S/EAST). Multiple logistic regression models were used for data analysis in Microsoft SPSS v.18. Type 1 error was considered equal to 0.05 .

Results: The average age of participants was $68.5 \pm 7.6$. Also, the prevalence of elder abuse in this study was 38.5 (95\% CI: $3.34-$ 42.3). After eliminating the confounders and applying multiple regression analysis, we found a significant association between elder abuse and factors such as education level $(\mathrm{OR}=2.003,95 \% \mathrm{CI}: 1.177-3.409)$, residence $(\mathrm{OR}=3.53,95 \% \mathrm{CI}$ : 1.969-6.324), and age $(\mathrm{OR}=0.963,95 \%$ CI: 0.931-0.995).

Conclusion: The results of this study indicated a high prevalence of elder abuse in the studied population. By identifying high-risk individuals for elder abuse and planning to improve their quality of life, we will be able to successfully overcome this issue.
\end{abstract}

Keywords: Elder, Elder abuse, Prevalence, Iran

Copyright@ Iran University of Medical Sciences

Cite this article as: Hosseinkhani Z, Moradi Zh, Khodamoradi F. Elder abuse: Screening in Iranian families. Med J Islam Repub Iran. 2017 (25 Dec);31:126. https://doi.org/10.14196/mjiri.31.126

\section{Introduction}

Statistics reveal a growing elderly population in the world. With regards to the WHO reports, elderly population is expected to rise from 900 million in 2015 to 2 billion in 2050 (1). Despite the high population of elders in developed societies, it is thought that the increase in population will be seen mostly in developing countries $(2,3)$. WHO has predicted that elderly population, which is now $8.2 \%$, will reach to $10.5 \%$ in 2025 and $21.7 \%$ in 2050 $(4,5)$. There are some factors affecting the life of elders including increase in their population, urbanization, and establishment of global village. With regards to social changes in human societies, such as women employment and increased poverty, it could be concluded that the possibility of elderly abuse will rise $(1,6,7)$.

Elder abuse includes physical, emotional, sexual abuse,

Corresponding author: Dr Farzad Khodamoradi,f_khodamoradi@yahoo.com

1. Social Determinants of Health Research Center, Qazvin University of Medical Sciences, Qazvin, Iran.

2. Department of Nursing, Takestan Medical Science Branch, Islamic Azad University, Takestan, Iran.

3. Health Services Management Research Center, Institute for Futures Studies in Health, Kerman University of Medical Sciences, Kerman, Iran.

4. Department of Epidemiology and Biostatistics, School of Public Health, Tehran University of Medical Sciences, Tehran, Iran. ignorance, abandon, and misuse of elders. It refers to a group of behaviors that hurt the elders or cause them serious problems and are performed by persons the elders trust. In addition, ignoring elders' care by not providing their essential needs and not protecting them from being hurt are included in this definition (8).

Elder abuse is also considered as an important public health problem in both developed and developing countries. Additionally, there is some evidence indicating that 1 to 10 elders experience this phenomenon every month (3). WHO has also reported that the prevalence of elder abuse is $1 \%$ to $15 \%$. Nowadays, there is a high rate of elder abuse reported all over the world. This probably has to do with the use of different tools $(7,9)$. A nationwide Canadian study reported that at least $4 \%$ of the population

$\uparrow$ What is "already known" in this topic:

Despite the Islamic advice about the necessity of respecting elders, their abuse has been remained a health and social issue, and only a small proportion of elders request help and use the facilities offered to them.

$\rightarrow$ What this article adds:

A large proportion of studies have been conducted in rich countries, however, this study showed the prevalence of elder abuse in Iran, a country in the Middle East. The factors such as age, education level, and residence of elders are associated with the prevalence of elder abuse. 
experienced elder abuse (10), while this was $44.7 \%$ in Cuba (11). Additionally, there is a $10.5 \%$ to $25 \%$ prevalence in Ahwaz, Iran (12). Since the majority of studies have been conducted in rich countries, little evidence is available about the prevalence of elder abuse in poor countries. Although the adverse social and ethical effects of elder abuse are observed in societies, there is still 1 per 24 underreporting rate; therefore, elder abuse can be described as "tip of the ice berg" and classified as a social problem with an increasing prevalence (13-15). Notably, these group of people often avoid expressing their problems. Therefore, identifying elder abuse, compared to other violence types, is more likely to fail $(3,13,16)$. With this in mind, to deal with elder abuse in the most appropriate way, we conducted this study to identify the features of elders who experienced abuse $(10,16,17)$.

\section{Methods \\ Participants}

This was a descriptive-analytic cross- sectional study, which was conducted in 2015. The target population was all the elders of Qazvin, Iran, who were selected by stratified multistage random sampling method. Elder care programs are provided as health services, especially in health centers, and also the elders are given health documents and are regularly admitted to these centers.

To select the samples, a list of health centers of Qazvin was extracted. Then, health centers were divided into 2 groups of rural and urban. They were considered as strata, and subsequently, the number of centers (strata) was determined in both groups. Next, elders in both groups were selected in a systematic random method and a "proportional to size" from the registries in which the care-related information had been documented. By calculating $\mathrm{p}=0.5$ and $\mathrm{d}=0.04$, the estimated sample size was 600 cases. Considering the design effect $=1.2$, the final sample size was 720 .

The inclusion criteria were age $>60$ years and the ability to go to health centers and respond to questions. The required information was obtained from the elders, who were involved (after getting the verbal consent) at the time of admission, and during the study period from September to December of 2015.

Variables definition are as follow: Elder abuse is a violent single or repeated act or lack of action, which may occur in relationships, where there is an assumption of reliance, resulting in harm, and distress in older persons $(2,13)$.

There are different types of elderly abuse, some of which are more common, such as (1) physical abuse, which may be observed when one uses violence to intimidate or physically hurt a vulnerable elder. (2) Emotional abuse is a type of abuse wherein verbal attacks, threats, rejection, isolation, or belittling acts might lead to mental anguish, pain, or distress in an elder. Neglect is defined as a situation in which a caregiver fails or refuses to provide safety and physical and emotional security for at risk elders (13).

\section{Data collection tool}

Hwalek-Sengstock Elder Abuse Screening Test was used as a standard questionnaire, containing 15 questions to identify those who have undergone abuse (or those who are at risk of abuse). This questionnaire includes 3 particular aspects of abuse: obviously executed violence, identification of potentially dangerous conditions, and at-risk people. These questions are also related to the determinants, treatment, emotional pressures of elders' life, and also the way of buying their requirements, physician admission, and being hurt. Elders with a score of 3 or more were classified as a group at risk of elder abuse (18).

To obtain the Persian version of the questionnaire, the original version was first independently translated by 2 Persian natives. After matching the translated versions, they were rechecked by an expert and back-translated into English by a skilled person. Then, the English version was matched with the original version, translated into the Persian, and approved by an expert. Finally, content validity was qualitatively performed for the final version (19).

Questionnaire's internal consistency (Cronbach's alpha coefficient) and reliability (intra-class correlations or ICC) were 0.74 and 0.71 , respectively, which were calculated after the pilot study and performed on 22 elders in a 2 week.

In addition to this specific questionnaire, elderly abuse was assessed in both demographic and economic aspects. Demographic features were age (as a continuous variable); gender; education (college, primary school, secondary school, high school, illiterate); marital status (single, married, divorced, widowed); job status (retired, have a job, pensioner, housewife); income (yes or no); number of children (daughters and sons); residence (rural, urban); living alone, with a partner, and so on; and house ownership (yes or no). The questionnaire was filled in through interviewing.

\section{Data analysis}

Sociodemographic characteristics of the elders were mentioned as frequency, percentage, mean, and standard deviation. The ratio of such variables as gender, marital status, occupation, education, residence, and income, number of children (separately for sons and daughters), house ownership, and life status was determined for the elders. Logistic regression analysis was used to identify the determinant factors for elderly abuse separately with measured covariates. Variables such as education, marital status, and job entered into the model as dummy variables; and illiteracy, being married and retirement were regarded as a baseline. Subsequently, to calculate the adjusted effect of each variable (with the elimination of confounders), they were entered (with p-value lower than 0.2 in former analysis) into the multiple logistic regression. The analysis was conducted using SPSS software Versions 18. Type 1 error was considered equal to 0.05 for the analysis.

\section{Results}

Of the total questionnaires, 37 were removed due to the imperfection of information. Therefore, 683 persons participated in this study (Response rate: $94.86 \%$ ). The 
Table 1. Demographic characteristics of elder participants in the study of elder abuse in 1394, Qazvin, Iran

\begin{tabular}{|c|c|}
\hline Characteristic & $\mathrm{N}$ (Percent) \\
\hline \multicolumn{2}{|l|}{ Gender } \\
\hline Male & $309(45.2)$ \\
\hline Female & $374(54.8)$ \\
\hline \multicolumn{2}{|l|}{ Marital status } \\
\hline Married or living with partner & $420(61.5)$ \\
\hline Widowed & $247(36.2)$ \\
\hline Divorced or separated & $11(1.6)$ \\
\hline Single/never married & $4(0.6)$ \\
\hline \multicolumn{2}{|l|}{ Job } \\
\hline Retired & $194(29.2)$ \\
\hline Housewife & $288(43.4)$ \\
\hline Have a job & 91 (13.7) \\
\hline Pensioner & 79 (11.9) \\
\hline Other & $12(1.8)$ \\
\hline \multicolumn{2}{|l|}{ Education } \\
\hline Illiterate & $424(62.1)$ \\
\hline Primary school & $170(24.9)$ \\
\hline Guidance school & $28(4.1)$ \\
\hline High school & $23(3.4)$ \\
\hline College & $38(5.6)$ \\
\hline \multicolumn{2}{|l|}{ Residence } \\
\hline Urban & $500(73.2)$ \\
\hline Rural & $182(26.6)$ \\
\hline \multicolumn{2}{|l|}{ Income (Monthly or yearly) } \\
\hline Yes & $442(64.7)$ \\
\hline No & $241(35.3)$ \\
\hline \multicolumn{2}{|l|}{ Number of children } \\
\hline \multicolumn{2}{|l|}{ Daughter } \\
\hline $0-2$ & $376(55)$ \\
\hline $3-5$ & $278(40.7)$ \\
\hline 6-8 & $29(4.3)$ \\
\hline \multicolumn{2}{|l|}{ Son } \\
\hline $0-2$ & $357(52.2)$ \\
\hline $3-5$ & $300(43.9)$ \\
\hline 6-8 & $26(3.9)$ \\
\hline \multicolumn{2}{|l|}{ Home ownership } \\
\hline Yes & $506(74.1)$ \\
\hline No & $177(25.9)$ \\
\hline \multicolumn{2}{|l|}{ Live } \\
\hline Alone & $136(19.9)$ \\
\hline With my partner & $403(59)$ \\
\hline With my son and his family & $95(13.9)$ \\
\hline With my daughter and her family & $26(3.8)$ \\
\hline Revolving home children & $9(1.3)$ \\
\hline Other & $14(2)$ \\
\hline
\end{tabular}

average age was $68.5 \pm 7.6$. Table 1 demonstrates the demographic characteristics of the participants.
Of the cases, $38.5 \%(3.34-42.3 \%)$ confirmed that they had experienced abuse, or are susceptible to abuse.

Crude and adjusted odds ratios measurement were calculated and illustrated in Tables 2 and 3. Both analysis methods revealed a significant association between education level and elder abuse, and as cases with primary education showed, the odds of elder abuse were 2 times more in illiterate elders.

In both analysis, sex and marital status were not found to have a significant association with elder abuse. By logistic regression analysis, housewives, compared to retired women, were $50 \%$ less susceptible to elder abuse. Multiple regression analysis revealed no significant association between job status and elder abuse. Conversely, a significant association was found between residence status and elder abuse $(\mathrm{OR}=3.53,95 \% \mathrm{CI}$ : 1.969-6.324). It means that those who were living in urban areas showed 3 times more susceptibility for elder abuse than those living in rural areas. Age was found to have a significant association with elder abuse (OR $=0.963,95 \% \mathrm{CI}$ : 0.931-0.995). Statistical analyses did not show any significant association between elder abuse and elders' income; also, the odds of elder abuse were not significantly different between the elders with income and those without any income.

\section{Discussion}

Insufficient attention has been paid to elder abuse overtime. This has been due to the personal characteristics of individuals and families circumstances (16). We found a 38.5 (95\% CI: $3.34-42.3$ ) rate of elder abuse occurrence and possibility. The rate of elder abuse has been reported to be $3.2 \%$ to $27.5 \%$ in population-based studies, implying a virtual diversity of elder abuse in different cultures (7). In Strasser et al. and Martins et al. studies, 33\% and $23.5 \%$ of the cases mentioned the experience of abuse at least for one time, respectively $(7,9)$. Increased number of elders appears to result in not only increased rate of exposure to chronically affected individuals, but also in increased rate of abuse $(9,20)$. Increase in life expectancy, reduction in family size, generational and communicational gaps between elders and other members of the family,

Table 2. Univariate logistic regression analysis between measured covariates and elder abuse in 1394, Qazvin, Iran.

\begin{tabular}{|c|c|c|c|c|c|}
\hline Covariates & OR & $95 \% \mathrm{CI}$ & $\mathrm{B}$ & Wald & $\mathrm{p}$ \\
\hline $\begin{array}{l}\text { Sex } \\
\text { (male vs. female) }\end{array}$ & 1.065 & {$[0.781-1.452]$} & 1.065 & 0.158 & 0.691 \\
\hline \multicolumn{6}{|l|}{ Education } \\
\hline (primary school vs. illiterate) & 0.138 & {$[0.048-0.397]$} & -1.979 & 13.548 & $<0.001$ \\
\hline (guidance school vs. illiterate) & 0.280 & {$[0.094-0.831]$} & -1.273 & 5.264 & 0.022 \\
\hline (high school vs. illiterate) & 0.294 & {$[0.078-1.102]$} & -1.224 & 3.296 & 0.069 \\
\hline (college vs. illiterate) & 0.269 & {$[0.069-1.053]$} & -1.313 & 3.556 & 0.059 \\
\hline \multicolumn{6}{|l|}{ Marital status } \\
\hline (widowed vs. married) & 5.852 & {$[0.603-56.769]$} & 1.767 & 2.323 & 0.128 \\
\hline (divorced vs. married) & 3.806 & {$[0.390-37.101]$} & 1.336 & 1.323 & 0.250 \\
\hline (single vs. married) & 0.667 & {$[0.043-10.253]$} & -0.405 & 0.085 & 0.771 \\
\hline \multicolumn{6}{|l|}{ Job } \\
\hline (Housewife vs. retired) & 0.553 & {$[0.377-0.811]$} & -0.593 & 9.186 & 0.002 \\
\hline (have a job vs. retired) & 0.957 & {$[0.560-1.636]$} & -0.044 & 0.026 & 0.873 \\
\hline (Pensioner vs. retired) & 0.679 & {$[0.393-1.172]$} & -.0387 & 1.932 & 0.165 \\
\hline (Other vs. retired) & 2.239 & {$[0.476-10.531]$} & 0.806 & 1.041 & 0.308 \\
\hline \multicolumn{6}{|l|}{ Residence } \\
\hline (Urban vs. rural) & 1.766 & {$[1.225-2.547]$} & 0.569 & 9.280 & 0.002 \\
\hline
\end{tabular}




\begin{tabular}{|c|c|c|c|c|c|}
\hline \multicolumn{6}{|l|}{ Income } \\
\hline (No vs. Yes) & 1.001 & [1.000-1.001] & 0.001 & 8.618 & 0.003 \\
\hline Age & 0.972 & [0.952-0.993] & -0.028 & 6.638 & 0.010 \\
\hline \multicolumn{6}{|c|}{ Table 3. Multiple logistic regression analysis between measured covariates and elder abuse in 1394, Qazvin, Iran } \\
\hline \multicolumn{6}{|l|}{ Education } \\
\hline (Primary school vs. illiterate) & 2.003 & [1.177-3.409] & 0.695 & 6.550 & 0.010 \\
\hline (Guidance school vs. illiterate) & 1.960 & {$[0.703-5.466]$} & 0.673 & 1.655 & 0.198 \\
\hline (High school vs. illiterate) & 1.435 & {$[0.510-4.043]$} & 0.361 & 0.468 & 0.494 \\
\hline (College vs. illiterate) & 6.392 & [1.743-23-443] & 1.855 & 7.826 & 0.005 \\
\hline \multicolumn{6}{|l|}{ Job } \\
\hline (Housewife vs. retired) & 1.308 & {$[0.706-2.420]$} & 0.268 & 0.729 & 0.393 \\
\hline (Have a job vs. retired) & 1.052 & [0.581-1.905] & 0.051 & 0.028 & 0.866 \\
\hline (Pensioner vs. retired) & 1.508 & {$[0.782-2.910]$} & 0.411 & 1.502 & 0.220 \\
\hline (Other vs. retired) & 8.314 & {$[0.932-74.214]$} & 2.118 & 3.598 & 0.058 \\
\hline \multicolumn{6}{|l|}{ Residence } \\
\hline (Urban vs. rural) & 3.529 & [1.969-6.324] & 1.261 & 17.950 & $<0.001$ \\
\hline \multicolumn{6}{|l|}{ Income } \\
\hline (No vs. Yes) & 1.001 & {$[1.000-1.001]$} & 0.001 & 6.734 & 0.009 \\
\hline Age & 0.963 & {$[0.931-0.995]$} & -0.038 & 5.036 & 0.025 \\
\hline
\end{tabular}

especially, financial dependency of elder to their children, have all led to a familial challenge, which may result in lack of security and an unwelcome impact on elders (21). The economic status of elders is an important factor in determining the odds of abuse. In this study, there was a significant association between the odds of elder abuse in people with neither annual nor monthly income and those with either annual or monthly income; however, the odds ratio was not considerable $(\mathrm{OR}=1.001,95 \% \mathrm{CI}=1.00$ 1.001).

Indian and Chinese studies have not reported any relationship between economic status and elder abuse (22, 23). As personal, social, and economic characteristics have a great impact on elder abuse, those with a worse condition are more susceptible to poor health and may develop a desire for death. These facts can justify providing a much more medical, dental, and psychological care to the elderly population $(9,10,17,18)$.

We did not find any significant association between the odds of abuse in males and females, unlike some similar studies $(14,16,22,24)$. For example, in Taiwan, elder females, considering their particular traditional culture, generally receive a lower respect and attention and are silently suffering from abuse (25). However, in Strasser et al. study, they found that males showed the criteria of abuse 5 times higher than females (9).

We found no significant association between marital status and elder abuse. No significant association was found in a similar study in Canada (10). However, in this study, there was a negative association between age and elder abuse. In this regard, studies have reported different results $(16,22,23)$. We also noticed that elders in rural areas were less likely to experience elder abuse. An Indian study reported similar results (14).

Elder abuse is a type of interpersonal violence, which can be committed by family members or relatives in different forms. As determining elder abuse rate is difficult $(7,11,26)$, it has remained a serious public health problem (2).

According to this study and other similar studies, 1 person out of 3 to 4 is at risk of elder abuse(7). Since the el- ders are not aware of punishments for those who commit elder abuse, and some other reasons (11, 16, 27), a small proportion of them ask for help and use the facilities provided for them. Therefore, with regards to the fact that elder abuse is often committed by relatives, controlling the behavior of people around the elders is highly important, as they may control the elders' phone conversations, separate them from the rest of the family, relatives, and friends, or threaten to leave them or send them to nursing homes. Some strange behaviors of elders, such as giving money to others as a gift or a loan, may result in unexpected changes in their economic status (for example, in some cases, they may lose a large portion of their wealth) and should also be considered (13).

Because abused elders are likely to refer to health centers, physicians are highly recommended to consult other specialists, legislators, social authorities, and social services (in the form of interprofessional-team) not only to successfully identify those elders who have been abused but also to manage this social problem better $(2,23)$. According to results of a Nigerian study, providing free medical services to the elders and jobs for children of the elders are suggested as an excellent solution. Therefore, their quality of life could be strengthened by improving their economic, health, and social status, albeit it is highly crucial to perfectly gather information about the burden of elder abuse in our population (6). This could be achieved by encouraging elders to appropriately execute "whistleblowing" in cases of abuse $(5,28)$.

\section{Conclusion}

Despite the Islamic advice about the necessity of respecting elders, elder abuse has remained a health and social issue. In addition, because of changes in the family structure, a large proportion of elders are likely to be abused, which is in opposition with Iranian culture. In conclusion, appropriate strategies for identifying and fighting the risk factors are highly recommended.

Study limitations: One of the most important limitations of this study and similar studies was the lack of unified understanding in the definition of elder abuse phenome- 
non and also the inability to identify the risk factors (17). In addition, the diversity of tools used in different studies can intensify this problem. Most importantly, those trying to receive more legal aid are more likely to be diagnosed, because in this case, being annoyed may make the elders to refer to health centers $(7,17)$. Therefore, as this study targeted elders who went to health centers, and as we did not assess the rate of abuse in disabled individuals who could not be admitted, selection bias and overestimation might have affected the results. Thus, health centers were selected for data collection because they included a significant population of elders for executing care programs, and the elders were regularly referred to these centers.

\section{Acknowledgments}

The authors offer their thanks to the Department of Health of Qazvin University of Medical Sciences for their cooperation in data collection. This study was approved by the Ethics Committee of Qazvin University of Medical Sciences and supported by a grant from the deputy for research of the mentioned university.

\section{Conflict of Interests}

The authors declare that they have no competing interests.

\section{References}

1. World Health Organization. Ageing and life-course. Elder abuse. 2016 [5 December 2016]. Available from: www.who.int/ageing/ projects/elder_abuse/en/.Menu

2. World Health Organization. Media centre. Elder Abuse. 2016[4 November 2016]. Available from: www.who.int/mediacentre/ factsheets/fs357/en/.

3. World Health Organization. A global response to elder abuse and neglect: building primary health care capacity to deal with the problem worldwide: main report. 2016 [4 November 2016]. Available from: www.who.int/ageing/publications/ELDER_Doc.

4. Motlagh M, Yazdani Sh, Taheri Tanjani P. Elderly health profile in Islamic republic of Iran. Teahran: Ministry of health and medical education: 2014. pp. 11-19.

5. World Health Organization. A strategy for active, healthy ageing and old age care in the Eastern Mediterranean Region 2006-2015. 2016[11 October 2016]. Available from: applications.emro.who. int/dsaf/dsa542.pdf.

6. Cadmus EO, Owoaje ET, Akinyemi OO. Older persons' Views and experience of elder abuse in south western Nigeria: A communitybased qualitative survey. JAH. 2015;27(4):711-29.

7. Cooper C, Selwood A, Livingston G. The prevalence of elder abuse and neglect: a systematic review. Age and ageing. 2008;37(2):15160.

8. Pillemer K, Finkelhor D. The prevalence of elder abuse: a random sample survey. Gerontologist. 1988;28(1):51-57.

9. Strasser SM, Smith M, Weaver S, Zheng S, Cao Y. Screening for Elder Mistreatment among Older Adults Seeking Legal Assistance Services. WestJEM. 2013;14(4):309-15.

10. Podnieks E. National Survey on Abuse of the Elderly in Canada, J Elder Abuse Negl. 1993;4(1-2):5-58.

11. Ribot VC, Rousseaux E, Garcia TC, Arteaga E, Ramos M, Alfonso M. Psychological the most common elder abuse in a Havana neighborhood. MEDICC review. 2015;17(2):39-43

12. Karimi M, Elahi N. Elderly abuse in Ahwaz city and its relationship with individual and social characteristics. Salmand. 2008;3(1):42-47.

13. Questions \& Answers about Elder Abuse. National Center on Elder Abuse Washington, DC. 2016[11 December 2016]. Available from: https://ncea.acl.gov/resources/docs/archive/15-QA-ElderAbuse-2005. pdf.

14. Kaur J, Kaur J, Sujata N. Comparative study on perceived abuse and social neglect among rural and urban geriatric population. Indian $\mathrm{J}$.
Psychiatry. 2015;57(4):375-8.

15. Sethi D, Jordanova Peshevska D. Preventing interpersonal violence in Europe. MJMS. 2014;7(2):246-248.

16. Martins R, Neto MJ, Andrade A, Albuquerque C. Abuse and maltreatment in the elderly. Atencion primaria. 2014;46 Suppl 5:206-9.

17. Anthony EK, Lehning AJ, Austin MJ, Peck MD. Assessing elder mistreatment: instrument development and implications for adult protective services. J Gerontol Soc Work. 2009;52(8):815-36.

18. Neale AV, Hwalek MA, Scott RO, Stahl C. Validation of the Hwalek-Sengstock elder abuse screening test. J Appl Gerontol 1991;10(4): 406-415.

19. Cull A, Sprangers M, Bjordal K, Aaronson N, West Km, Bottomley, A. EORTC quality of life group translation procedure (2nd edn). Brussels: EORTC. 2002.

20. AlShaali A, AlJaziri A. Health profile of elderly patients registered in the Elderly Home Based Primary Care, Dubai, United Arab Emirates. ME-JAA. 2015;12(1):13-19.

21. Gupta A, Mohan U, Singh SK, Manar MK, Tiwari SC, Singh VK. Screening Depression among Elderly in a City of Southeast Asia. JCDR. 2015;9(9):Lc01-5.

22. Saikia AM, Mahanta N, Mahanta A, Deka AJ, Kakati A. Prevalence and Risk Factors of Abuse among Community Dwelling Elderly of Guwahati City, Assam. IJCM: official publication of Indian Association of Preventive \& Social Medicine. 2015;40(4):279-81.

23. Dong X. Elder abuse in Chinese populations: a global review. Elder Abuse Negl. 2015;27(3):196-232.

24. Elder Abuse in the Family in Spain. 2016[12 November 2016]. Available from: http://www.inpea.net/images/Spain_Report_2008_ Elder.

25. Cho CY. Silent Victims: A Brief Report on Abused Older Women in Taiwan. Elder Abuse Negl. 2015;27(4-5):514-26.

26. Krug EG, Mercy JA, Dahlberg LL, Zwi AB. The world report on violence and health. The Lancet. 2002;360(5):1083-1089.

27. Knight BG, Kim S, Rastegar S, Jones S, Jump V, Wong S. Influences on the perception of elder financial abuse among older adults in Southern California. Int Psychogeriatr. 2016;28(1):163-9.

28. Phelan A. Protecting care home residents from mistreatment and abuse: on the need for policy. Risk management and healthcare policy. 2015;8:215-23. 